Biomath Forum

\title{
A Generic Modeling of Fire Impact in a Tree-Grass Savanna Model
}

\author{
A. Tchuinté Tamen*, J. J. Tewa*, P. Couteron ${ }^{\dagger}$, S. Bowong*, Y. Dumont ${ }^{\ddagger}$ \\ *UMI 209 UMMISCO, GRIMCAPE, Yaounde, Cameroon \\ Email: tamenalexis@yahoo.fr; tewajules@gmail.com; sbowong@gmail.com \\ ${ }^{\dagger}$ IRD, Umr AMAP, Montpellier, France \\ Email: pierre.couteron@ird.fr \\ ${ }^{\ddagger}$ CIRAD, Umr AMAP, Montpellier, France \\ Email: yves.dumont@cirad.fr
}

Received: 12 November 2013, accepted: 19 July 2014, published: 28 August 2014

\begin{abstract}
We propose and study a model for treegrass interactions in the context of savannas which are subjected to fire pressure. Several theoretical models in the literature which have highlighted the impact of fire on tree-grass interactions did not explicitly deal with the indirect feedback of dry grass biomass onto tree dynamics through fire intensity and frequency. The novelty in our work is to consider a fairly generic modeling of fire impact on woody biomass by means of a family of increasing and bounded functions of grass biomass. The characteristic feature of this family of functions is that, it could include several forms: linear as well as non-linear ones (sigmoidal or not). Since the nonlinear shape brings more diverse results than the previous attempts using a linear function, it could be used to show that several vegetation equilibria exist with some of them showing tree-grass coexistence features. We show that the number of equilibria with both grass and trees depends on the choice of the fire impact function. We also established thresholds defining the stability domains of the equilibria and highlighted some bifurcation parameters to provide numerical simulations complying with the theoretical properties of the model.
\end{abstract}

Keywords-Savanna Modeling; Tree-Grass interactions; Stability; Nonstandard Finite Difference Method; Bifurcation.

\section{INTRODUCTION}

Savannas are complex ecosystems mixing trees and grasses to create physiognomies that are neither grassland nor forest [44]. Savannas occur in areas where the mean annual temperature is higher than $17^{\circ} \mathrm{C}$ and where mean annual rainfall is between 250 and $2100 \mathrm{~mm}$ [60]. For instance, the mean annual rainfall is between 1350 and 1400 $\mathrm{mm}$ [48], [61], for the regions between Mbam and Sanaga in Cameroon, where the so-called "soudano-guinean" savannas dominate [28].

Africa contains by far the largest area of savannas, with as much as 15.1 million $\mathrm{km}^{2}$, or $50 \%$ of the continent surface [15], [31]. In Central Africa, savannas spread across Northern Cameroon, Southern Chad and the Central African Republic. Furthermore, a large share of these central African savannas fringes extensive areas of moist tropical forests, as do littoral savannas which 
spread from the plains of Gabon to DCR and Angola [19], or inside the continent, the Nairi and Bateke savannas which extend soudano-zambezian vegetation from Angola up to Gabon [27]. All these savannas observed under humid climates are rather prone to fires which tend to counteract natural reforestation. Most often at times, because savannas are frequently burned and occupy wide areas, their management may influence the regional and possibly global energy, water and carbon balances [40], [41].

During the last decades, various explanations of the long-lasting coexistence of trees and grasses mixtures in savannas have been proposed. Some of them invoke limiting resources (soil moisture or nutrients) and possible niche separation of rooting zones that could result in differential access to limiting resources between tree and grass [26], [55], [57], [58]. Other explanations emphasized the role of disturbance regimes in preventing trees to reach canopy closure [2], [23], [44]. [38] showed that limiting water resource is probably pervasive in the driest part of the rainfall gradient while disturbances (fire, herbivory) are probably central to tree-grass coexistence under wetter climates. Among these disturbances, fire is recognized as quintessential since it is able to suppress young trees and shrubs that lay within the flame zone thereby preventing them to reach maturity [11], [37], [38] and depress grass biomass by shading [29], [43]. In savanna environment, fire intensity is tightly linked to the dried grass biomass that remains during the dry season. Large trees having crowns above the flame zone (say $2 \mathrm{~m}$ high) are rarely affected by fires, but recurrent fires prevent a great number of these trees from escaping the flame zone, and tree biomass becomes sufficiently low to have no depressure effect on grass biomass production. This feedback loop between grass production and fire intensity is a key pattern of savanna ecosystems that are observed under sufficiently wet climates [47].

Since tree-grass coexistence involves complex retroactions which are moreover contextdependent, modeling has to play an important role to understand dynamical processes that shape savanna vegetation. Several recent modeling efforts have built on systems of ordinary differential equations expressing the asymmetric competition between tree and grass. In this line of research initiated by [52], the superior competitor (mature tree) is the one that always displaces the inferior competitor (grass) when they both occur in a site, and the inferior competitor can neither invade nor displace the superior competitor from a site. However, the coexistence of trees and grass and to a lesser extent the dominance of grass over trees can result from the suppression of tree seedlings by grass competition in a way either direct or fire-mediated. Indeed, a mathematical analysis of Tilman's and derived models shows that it is possible to have a globally asymptotic stable (GAS) tree-grass equilibrium.

Consequently, we found it desirable to consider modeling options of fire as follows:

(i) split fire frequency from fire intensity. Since fire intensity increases principally with grass abundance [47], while fire frequency also depends on management choices.

(ii) use distinct functions of fire impact on grass vs. woody biomass, since it is observed that, grasses and trees are affected differently.

(iii) allow for various conditions of bistability in order to render the diversity of physiognomies that are observed in the field.

We will show that this last condition may be ensured by incorporating a fairly generic modeling of the impact of fire on woody biomass, by means of a family of functions which could take linear or non-linear shapes. We will also establish that the number of equilibria with tree-grass coexistence depends on the characteristics of the function.

Our aim in the present paper is therefore to propose a new tree-grass model following the above objectives and achieve a complete theoretical analysis of this model. We shall highlight three thresholds that summarize the dynamics of the system. We shall equally illustrate the theoretical results through numerical simulations, obtained with an appropriate nonstandard finite difference scheme 
complying with the theoretical properties of the model. We will also highlight some bifurcation parameters.

\section{The Mathematical Model}

Consider the following simple model of treegrass dynamics taking into account fire as continuous events:

$$
\left\{\begin{array}{l}
\frac{d G}{d t}=\left(\gamma_{G}-\delta_{G 0}\right) G-\mu_{G} G^{2}-\gamma_{T G} T G-\lambda_{f G} f G, \\
\frac{d T}{d t}=\left(\gamma_{T}-\delta_{T}\right) T-\mu_{T} T^{2}-\lambda_{f T} f \omega(G) T,
\end{array}\right.
$$

with, $T(0)=T_{0}$ and $G(0)=G_{0}$ positive initial conditions, $T$ and $G$ are Tree and Grass biomasses $\left(t . h a^{-1}\right)$ respectively, $\gamma_{T}$ and $\gamma_{G}$ are the Tree and Grass biomass productivity $\left(y r^{-1}\right)$. In our model, nutrients and water are modelled implicitly via competition and production terms of vegetation. $\delta_{T}$ and $\delta_{G 0}$ are the biomass loss by respiration and natural death, $\mu_{T}$ and $\mu_{G}$ are the additional death due to the intra-specific competition, $\gamma_{T G}$ is the mortality due to tree-grass competition, $f=\frac{1}{\tau}$ is the fire frequency with $\tau$ the period between two consecutive fires, $\lambda_{f T}$ and $\lambda_{f G}$ represent the specific loss of tree and grass biomasses due to fire, and $\omega(G)$ is the function of grass biomass which expresses the causality between grass biomass and fire intensity and models the impact of fire on the woody biomass.

For convenience, and with limited loss of generality, we make assumptions about $\omega(G)$. Other than smoothness it satisfies these following three conditions:

- $\omega(0)=0$,

- $\omega(G)>0$, and $\omega^{\prime}(G)>0$,

- $\lim _{G \rightarrow \infty} \omega(G)<\infty$.

\section{A. Some qualitative results of the system (1)}

To introduce this section, we first state, with proof, the existence and uniqueness lemma.

Lemma II.1. With the initial conditions $T(0)=$ $T^{0}$ and $G(0)=G^{0}$, system (1) has a unique maximal solution.
Proof: Let us set $X=(G, T)^{T} \in \mathbb{R}_{+}^{2}$, $F(X)=\left(F_{1}(X), F_{2}(X)\right)^{T} \in \mathbb{R}^{2}$, and

$$
\left\{\begin{array}{l}
F_{1}(X)=\left(\gamma_{G}-\delta_{G 0}\right) G-\mu_{G} G^{2}-\gamma_{T G} T G-\lambda_{f G} f G, \\
F_{2}(X)=\left(\gamma_{T}-\delta_{T}\right) T-\mu_{T} T^{2}-\lambda_{f T} f \omega(G) T .
\end{array}\right.
$$

System (1) becomes

$$
\frac{d X}{d t}=F(X)
$$

with $X(0)=\left(G^{0}, T^{0}\right)^{T}$.

$\mathrm{F}$ is a continuously differentiable map $\left(\mathcal{C}^{1}\right)$, because $F_{1}$ and $F_{2}$ are $\mathcal{C}^{1}$. Then, by the CauchyLipschitz theorem, system (1) with the initial condition $X(0)=X^{0}$ admits a unique maximal solution.

Models require that trajectories remain positive and that trajectories do not tend to infinity with increasing time. If the set $S$ is such that all trajectories that start in $S$ remain in $S$ for all positive time, then $S$ is said to be "positively invariant". (If trajectories remain in $S$ for both positive and negative time, $S$ is said to be invariant). Hence, the basic condition for positivity (of dependent variables) can be stated as "the positive cone is positively invariant for the dynamical system generated by system (1)".

Lemma II.2. The positive cone $\mathbb{R}_{+}^{2}$ is positively invariant for the system (1).

Proof: $G=0$, and $T=0$ are vertical and horizontal null clines respectively. Then, no trajectory can cut these axes. Thus, $\mathbb{R}_{+}^{2}$ is positively invariant for (1) because, all trajectories that start in $\mathbb{R}_{+}^{2}$ remain in $\mathbb{R}_{+}^{2}$ for all positive time.

The dynamical system is said to be "dissipative" if all positive trajectories eventually lie in a bounded set. This is sufficient to ensure that all solutions of system (1) exist for all positive times.

Lemma II.3. The compact $\Gamma$, given by

$$
\left\{(G, T)^{T} \in \mathbb{R}_{+}^{2} / T \leq \frac{\gamma_{T}-\delta_{T}}{\mu_{T}}, G \leq \frac{\gamma_{G}-\delta_{G 0}-\lambda_{f G} f}{\mu_{G}}\right\}
$$

is attracting for system (1) (e.g., all trajectories of system (1) that reach the neighbourhood of $\Gamma$ 
A. Tchuinté Tamen et al., A Generic Modeling of Fire Impact in a Tree-Grass Savanna Model...

converge inside for all positive time). $\Gamma$ is call the $\omega$-limit set.

Proof: From system (1), with initial conditions $T(0)=T^{0}>0$ and $G(0)=G^{0}>0$, we have

$$
\left\{\begin{array}{l}
\frac{d G}{d t} \leq\left(\gamma_{G}-\delta_{G 0}-\lambda_{f G} f\right) G-\mu_{G} G^{2} \\
\frac{d T}{d t} \leq\left(\gamma_{T}-\delta_{T}\right) T-\mu_{T} T^{2} \\
G(0)=G^{0} \\
T(0)=T^{0}
\end{array}\right.
$$

Using the maximum principle, we deduce that

$$
\left\{\begin{array}{l}
G(t) \leq \frac{G^{0}}{\frac{G^{0}}{G_{e}}+\left(1-\frac{G^{0}}{G_{e}}\right) \exp \left\{-G_{e} \mu_{G} t\right\}}, \\
T(t) \leq \frac{T^{0}}{\frac{T^{0}}{T_{e}}+\left(1-\frac{T^{0}}{T_{e}}\right) \exp \left\{-T_{e} \mu_{T} t\right\}},
\end{array}\right.
$$

where, $G_{e}=\frac{\gamma_{G}-\delta_{G 0}-\lambda_{f G} f}{\mu_{G}}$ and $T_{e}=$ $\frac{\gamma_{T}-\delta_{T}}{\mu_{T}}$.

We obtain,

$$
\left\{\begin{array}{l}
\lim _{t \rightarrow+\infty} G(t) \leq G_{e}=\frac{\gamma_{G}-\delta_{G 0}-\lambda_{f G} f}{\mu_{G}}, \\
\lim _{t \rightarrow+\infty} T(t) \leq T_{e}=\frac{\gamma_{T}-\delta_{T}}{\mu_{T}} .
\end{array}\right.
$$

Then, all trajectories of system (1) that reach the neighbourhood of $\Gamma$ converge inside as $t$ tends to infinity. Thus $\Gamma$ is attracting for the system (1).

Let $\psi: \mathbb{R}^{2} \times \mathbb{R} \rightarrow \mathbb{R}^{2}$ be a function of two variables, such as $\psi(y, t)=X(t)$, where $\mathrm{X}(\mathrm{t})$ is the solution of system (3) satisfying the initial condition $\mathrm{X}(0)=\mathrm{y}$.

Definition II.1. In the terminology of dynamical systems, a steady state or an equilibrium point of system (3) is an element $P \in \mathbb{R}_{+}^{2}$ such that $\psi(P, t)=P$ for all $t \in \mathbb{R}$. Similarly, a periodic orbit is one that satisfies $\psi(P, t+T)=P$ for all $t$ and for some fixed number $T$. The corresponding solution of system (3) will be a periodic function.

It is observed that, system (1) admits these following nonnegative equilibria,

- $(0 ; 0)$ corresponding to bare soil (always unstable),

- $E_{T_{e}}=\left(0 ; T_{e}\right)=\left(0 ; \frac{\gamma_{T}-\delta_{T}}{\mu_{T}}\right)$, i.e., a wooded savanna equilibrium,

- $E_{G_{e}}=\left(G_{e} ; 0\right)=\left(\frac{\gamma_{G}-\delta_{G 0}-\lambda_{f G} f}{\mu_{G}} ; 0\right)$, i.e., a grassland savanna,

- $E^{*}=\left(G^{*} ; T^{*}\right)$, i.e., the tree-grass coexistence equilibrium.

In biological systems, eventual behaviours and asymptotic properties of trajectories need to be determined. It is also important to know when limit cycle (periodic solution) occurs or not.

Lemma II.4. There is no limit cycle for system (1) in the positive cone $\mathbb{R}_{+}^{2}$.

Proof: Let $(G, T)^{T} \in \mathbb{R}_{+}^{2}$, and

$$
\beta(T, G)=\frac{1}{T G} \text {. }
$$

We have,

$$
\begin{aligned}
& \beta F_{1}=\frac{\left(\gamma_{G}-\delta_{G 0}-\lambda_{f G} f\right)-\mu_{G} G-\gamma_{T G} T}{T} \\
& \beta F_{2}=\frac{\left(\gamma_{T}-\delta_{T}\right)-\mu_{T} T-\lambda_{f T} f \omega(G)}{G} .
\end{aligned}
$$

Then,

$$
\frac{\partial \beta F_{1}}{\partial G}+\frac{\partial \beta F_{2}}{\partial T}=-\frac{\mu_{G}}{T}-\frac{\mu_{T}}{G}<0 .
$$

Using Dulac criterion, we conclude that, system (1) has no periodic solution in $\mathbb{R}_{+}^{2}$.

Concerning the stability thresholds of equilibria, the following proposition holds.

Proposition II.1. The stability of the equilibria depends on the following thresholds: 
A. Tchuinté Tamen et al., A Generic Modeling of Fire Impact in a Tree-Grass Savanna Model...

- $\mathcal{R}_{10}=\frac{\gamma_{T}-\delta_{T}}{\lambda_{f T} f} \frac{1}{\omega\left(G_{e}\right)}$, related to the savanna vs. grassland equilibrium. It is an increasing function of tree biomass. It represents the net production of tree biomass relative to the fire-induced biomass loss at the grassland equilibrium.

- $\mathcal{R}_{01}=\frac{\gamma_{G}-\delta_{G 0}-\lambda_{f G} f}{\gamma_{T G}} \frac{\mu_{T}}{\gamma_{T}-\delta_{T}}$, related to the savanna vs. forest equilibrium. It represents the net primary production of grasses after fire, relative to the grass production loss due to the tree biomass at the wooded savanna equilibrium.

- $\mathcal{R}_{11}^{*}=\mathcal{R}_{10} \mathcal{R}_{01} \frac{\omega\left(G_{e}\right)}{\omega^{\prime}\left(G^{*}\right) G_{e}}$, related to the mixed tree-grass equilibrium.

Proof: See appendix A.

Remark II.1. There is an obvious relation between the last threshold and the two previous ones. These thresholds are positive considering the reasonable ecological parameters.

1) Model without fire: When fire frequency $f=0$ (Tilman's model), all equilibria and their related stability properties are summarized in Table I.

TABLE I: Stability/Instability results for Tilman's Model

\begin{tabular}{|c|c|c|c|c|}
\hline Threshold & Conditions & $\begin{array}{c}\text { Ecological } \\
\text { equilibria }\end{array}$ & $\begin{array}{c}\text { Stable } \\
\text { equilibria }\end{array}$ & $\begin{array}{c}\text { Unstable } \\
\text { equilibria }\end{array}$ \\
\hline \multirow{4}{*}{$\mathcal{R}_{01}$} & $<1$ & $(0 ; 0), E_{T_{e}}$, & $\begin{array}{c}E_{T e} \\
\text { and } E_{G_{e}}\end{array}$ & $(0 ; 0)$, \\
& $>1$ & $(0 ; 0), E_{G_{e}}$ & $\left.E^{*}\right)$ & $E_{G_{e}}$ \\
\cline { 2 - 5 } & & $E_{T_{e}}$, and $E^{*}$ & $(\mathrm{GAS})$ & $E_{G_{e}}, E_{T_{e}}$ \\
\hline
\end{tabular}

Table I means that, without fire, when the threshold $\mathcal{R}_{01}<1$, trees grow toward their carrying capacity $E_{T_{e}}$, while it is not the case for grass. This can be explained by the fact that, tree canopy reduces light availability which is necessary for grass growth. Then, when the shading effect is higher, only trees can persist. This is supported by studies demonstrating that competition effects of grass are not strong enough to prevent rapid recruitment of trees into savannas when fire is excluded [23], [44]. On the other hand, when, $\mathcal{R}_{01}>1$, the tree-grass node exists and is GAS, while $E_{T_{e}}$ becomes unstable. Then, the Tilman's two-species model exhibits the transcritical bifurcation. These results join those in [17]. Thus, if trees and grass in savanna are not inflammable, there is only one possible bifurcation namely a transcritical bifurcation.

2) Model with continuous fire forcing : We now investigate system (1) with $f \neq 0$ in order to determine whether multiple stable states exist and analyze how the system can veer off from a stable equilibrium to another depending on some thresholds parameters.

$\star$ Let us consider $\omega(G)=G$ as assumed in [55].

We summarize all the results in the Table II bellow

TABLE II: Stability/Instability results when $\omega(G)=G$.

\begin{tabular}{|c|c|c|c|c|c|}
\hline \multicolumn{3}{|c|}{ Conditions } & $\begin{array}{c}\text { Ecological } \\
\text { Equilibria }\end{array}$ & $\begin{array}{c}\text { Stable } \\
\text { Equilibria }\end{array}$ & $\begin{array}{c}\text { Unstable } \\
\text { Equilibria }\end{array}$ \\
\hline \multirow[b]{2}{*}{$\mathcal{R}_{10}>1$} & $\mathcal{R}_{01}>1$ & $\mathcal{R}_{11}^{*}>1$ & $\begin{array}{l}\quad(0 ; 0) \\
E_{T_{e}}, E_{G e} \\
\quad \text { and } E^{*}\end{array}$ & $E^{*}(\mathrm{GAS})$ & $\begin{array}{c}(0 ; 0), \\
E_{G_{e}}, \\
\text { and } E_{T_{e}}\end{array}$ \\
\hline & $\mathcal{R}_{01}<1$ & - & $\begin{array}{c}(0 ; 0) \\
E_{G_{e}}, E_{T_{e}}\end{array}$ & $E_{T_{e}}(\mathrm{GAS})$ & $\begin{array}{c}(0 ; 0) \text {, } \\
\text { and } E_{G_{e}}\end{array}$ \\
\hline \multirow[b]{2}{*}{$\mathcal{R}_{10}<1$} & $\mathcal{R}_{01}>1$ & - & $\begin{array}{c}(0 ; 0) \\
E_{G_{e}}, E_{T_{e}}\end{array}$ & $E_{G_{e}}(\mathrm{GAS})$ & $\begin{array}{c}(0 ; 0), \\
\text { and } E_{T_{e}}\end{array}$ \\
\hline & $\mathcal{R}_{01}<1$ & $\mathcal{R}_{11}^{*}<1$ & $\begin{array}{c}(0 ; 0) \\
E_{T_{e}}, E_{G_{e}} \\
\quad \text { and } E^{*}\end{array}$ & $\begin{array}{c}\text { Bi-stability } \\
E_{G_{e}} \text { (LAS) } \\
E_{T_{e}} \text { (LAS) }\end{array}$ & $\begin{array}{c}(0 ; 0) \\
\text { and } \\
E^{*}\end{array}$ \\
\hline
\end{tabular}

Table II exhibits two different bifurcations. The first one is the same as in table I, say the transcritical bifurcation. More explicitly, when $\mathcal{R}_{01}<1$, the forest equilibrium $E_{T_{e}}$ is GAS, and becomes unstable when $\mathcal{R}_{01}>1$ while, the coexistence tree-grass equilibrium which is GAS exists. The second bifurcation is the pitchfork bifurcation. This previous bifurcation occurs because a unique coexisting equilibrium which is GAS exists when $\mathcal{R}_{11}^{*}>1$, and becomes unstable when $\mathcal{R}_{11}^{*}<1$ while, woodland and grassland equilibria are stable. The bistability between woodland and grassland equilibria corroborates with the theoretical results in [18]. However, the model without fire do not present this bistability. Then, fires, turn in favour of grass by damaging young trees and shrubs. These negative feedbacks of grass on trees through fires were considered by [44] which modelled the impact of fires on trees by differentiating tree compartment in two ways: sensitive trees (like 
A. Tchuinté Tamen et al., A Generic Modeling of Fire Impact in a Tree-Grass Savanna Model...

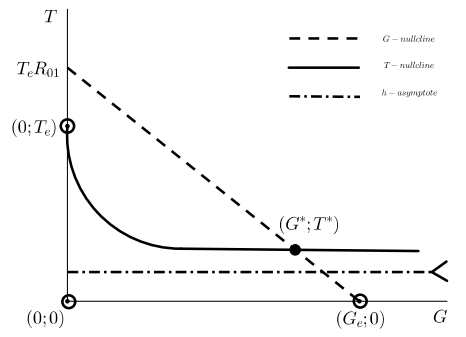

Fig. 1: Different Equilibria and their stability/instability properties when $\mathcal{R}_{01}>1$ and $\omega\left(G_{e}\right) R_{10}>1$. Solid circles indicate a stable equilibrium, and open circles indicate an unstable equilibrium. There are four equilibria. Only coexistence equilibrium is GAS (see Tables I and II).

shrubs) and non sensitive trees (mature trees). As a result, fire promotes tree-grass coexistence and the occurrence of bistability of woodland and grassland.

Let us recall that in our study $\omega(G)$ is a generic function. Our interest here is to explore to what extent the shape of $\omega(G)$ may favour multiple stable states and thereby explain the tendency of savannalike ecosystems to shift among different stable states. According to the choice of the response function $\omega(G)$, we obtain several configurations. For instance, as assumed in [2],

$$
\omega(G)=\frac{G^{\beta}}{G^{\beta}+\alpha^{\beta}},
$$

where $\alpha$ controls the location of the point where $\omega$ is half of its maximum value and $\beta$ controls the rate of increase of $\omega$. The particular cases of this function are the Holling functions type II and III which are also referred to the Michaelis-Menten function and the sigmoidal response function respectively. Here, to show various implications and configurations due to the choice of $\omega$, we have considered these previous two particular cases. The ecological models are developed and their mathematical properties are analyzed.

To simplify the calculations, we set $G_{0}=\alpha^{\beta}$.

$\star \star$ First, let us consider the Holling type II, and then six different configurations can arise depending on certain thresholds.

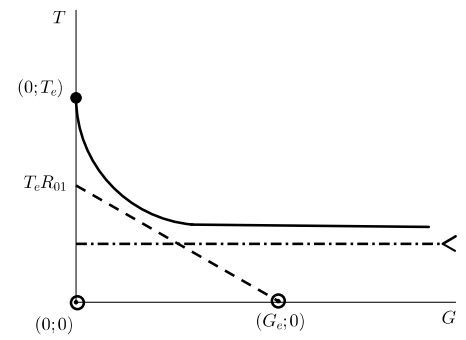

(a)

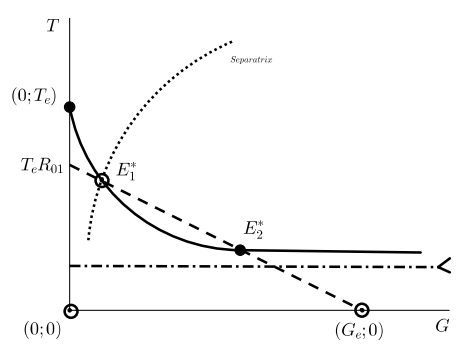

(b)

Fig. 2: Equilibria and their stability/instability properties when $\mathcal{R}_{01}<1$ and $\omega\left(G_{e}\right) R_{10}>1$. In (a), there is no coexistence and only wooded savanna equilibrium is GAS as in Table I and Table II. In (b), there are two internal equilibria: $E_{1}^{*}$ (unstable) and $E_{2}^{*}$ stable. A separatrix divides the plane into two basins of attraction: one to the stable woodland equilibrium; one to $E_{2}^{*}$ (bistability).

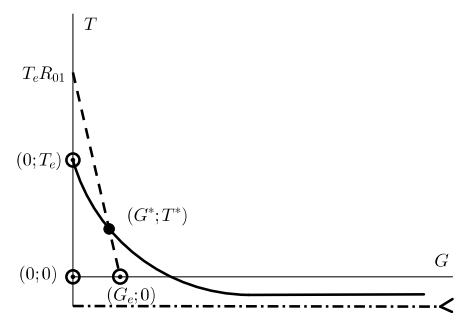

Fig. 3: Different equilibria and their stability/instability properties when $\mathcal{R}_{01}>1$ and $\omega\left(G_{e}\right) R_{10}<1$. Same as in Fig 1 there are four equilibria and only coexistence equilibrium is GAS.

Our analysis suggests that, using the Holling type II in Tilman's two-species model provides richer qualitative behaviour than the linear form. For instance two different coexistence equilibria can exist and bistability can occur to one of them with stable forest equilibrium. This result joins those of [1], [10], [22], [23] which modelled 


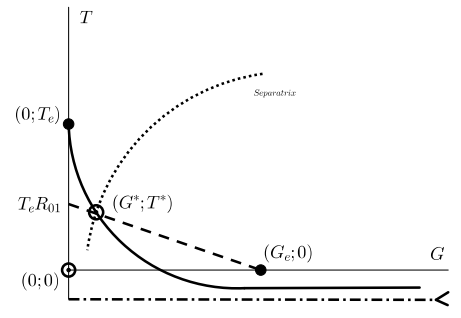

(a)

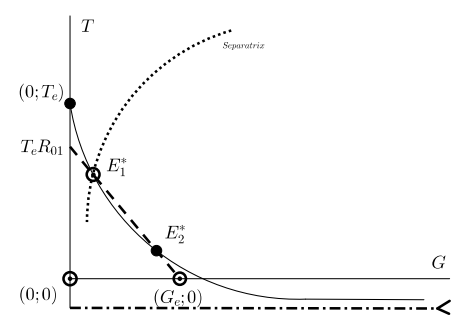

(b)

Fig. 4: Different equilibria and their stability/instability properties when $\mathcal{R}_{01}<1$ and $\omega\left(G_{e}\right) R_{10}<1$. (a) presents two basins of attraction divide by a separatrix: one to the stable grassland equilibrium; one to the stable woodland equilibrium (bistability as in Table II). (b) is the same as (b) in Fig 2 except with $\omega\left(G_{e}\right) R_{10}<1$.

savanna and forest as alternative stable states. Thus, trajectories of the model can evolve either to the woodland equilibrium or the coexistence equilibrium, depending on initial conditions.

$\star \star \star$ Now, we consider the Holling type III. Here we have seven configurations depending on certain thresholds.

Fig 7 is obtained when thresholds $\mathcal{R}_{01}$ and $\omega\left(G_{e}\right) R_{10}$ are greater than 1 . The first one $\mathcal{R}_{01}>$ 1 indicates that the net primary production of grasses after fire, relative to the grass production loss due to the tree biomass at the wooded savanna equilibrium. This competition turns in favour of trees (see Fig 6-(a) above). It leads to the existence of the upper coexistence equilibrium $E_{1}^{*}$ with higher tree biomass and lower grass biomass. This equilibrium represents the longlasting coexistence of trees and grass due to the inter-specific competition between grass and trees.

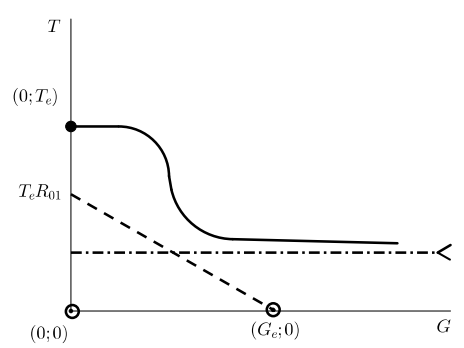

(a)

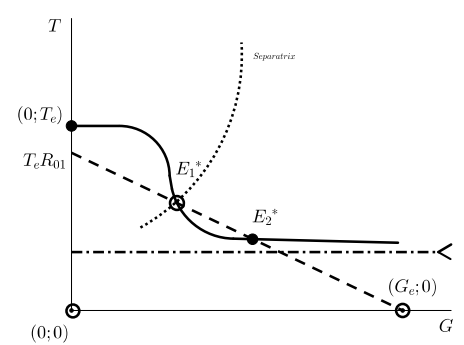

(b)

Fig. 5: Equilibria and their properties when $\mathcal{R}_{01}<1$ and $\omega\left(G_{e}\right) R_{10}>1$. Same as in Fig 2 In (a), there is no coexistence and only woodland equilibrium is GAS. In (b), there are two feasible internal equilibria. A separatrix divides the plane into two basins of attraction; one to the stable woodland equilibrium; and one to the lower internal equilibrium (bistability).

It is obvious that the threshold $\omega\left(G_{e}\right) R_{10}$ is linked to $R_{10}$ which represents the net production of tree biomass relative to the fire-induced biomass loss at the grassland equilibrium. When $\omega\left(G_{e}\right) R_{10}>1$, the lower coexistence equilibrium $E_{2}^{*}$ exists with lower tree biomass and higher grass biomass (see Fig 5-(b) above). $E_{2}^{*}$ represents the tree-grass coexistence due to the indirect feedback of grass on tree biomass through fire. Our interest in this section, was to show various configurations and implications due to the choice of $\omega$. In this case, we have considered two particular functions for $w(G)$ : Holling type II and type III. Following [47], we showed that these sigmoidal forms of $\omega(G)$ make multiple stable equilibria possible. There are between 0 and 3 internal equilibria and between 0 and 2 stable internal equilibria. In addition, we highlighted two specific thresholds $\mathcal{R}_{01}$ and $\omega\left(G_{e}\right) R_{10}$ which regulate different tree- 


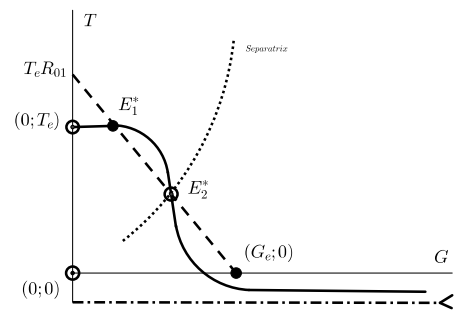

(a)

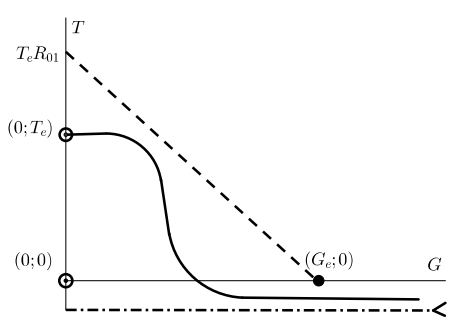

(b)

Fig. 6: Different equilibria and their stability/instability properties when $\mathcal{R}_{01}>1$ and $\omega\left(G_{e}\right) R_{10}<1$. Opposite to Fig 3 we have two situations. (a) shows two feasible internal equilibria, the lower equilibrium is unstable and the upper is stable. It presents the bistability between the upper coexistence equilibrium and the grassland equilibrium. We could not observe this situation previously, when we used the Holling type II or a linear form of $\omega$. Other point is that in (b), grassland is GAS. Note that this is not the case with Holling type II.

grass patterns. However, recall that in this work our function $\omega(G)$ is a generic one and therefore could take a linear or non-linear form. Concerning the above sigmoidal functions, the results indicate that Holling response type III qualitatively allows richer behaviours for the Tilman's model. To perform our simulations, some parameter values were based on the literature and others from the ecological plausible domains such that they obey the reality. The parameter values are summarized in table III.

\section{A NONSTANDARD ALGORITHM}

In order to keep all qualitative properties of our model, we design a nonstandard finite difference (NSFD) schemes ([3], [7], [33], [35]).

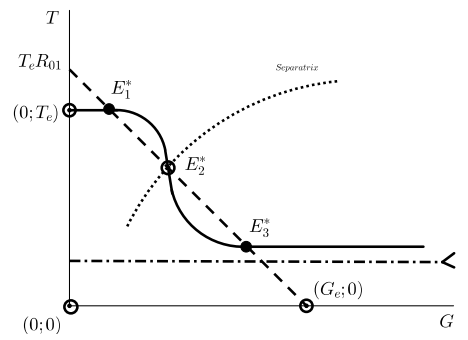

Fig. 7: Stability/instability properties of equilibria when $\mathcal{R}_{01}>1$ and $\omega\left(G_{e}\right) R_{10}>1$. Stable equilibria are shown with solid circles; unstable equilibria are shown with open circles. Opposite to Fig 1 there are three internal equilibria where the null clines meet. The intermediate equilibrium point is unstable and the lower and upper equilibria are stable. A separatix which divides the plane into two basins of attraction passes through the unstable equilibrium. Depending on the initial condition, trajectories will evolve either to the left or right (bistability).

TABLE III: Parameter values

\begin{tabular}{cccc}
\hline & Units & Values & References \\
\hline$f$ & $y r^{-1}$ & $0-1$ & {$[55]$} \\
$\gamma_{G}$ & $y r^{-1}$ & $0.4^{(1)}-4.6^{(2)}$ & $(1)[35]$ \\
& & & $(2)[32]$ \\
$\gamma_{T}$ & $y r^{-1}$ & $0.456-7.2$ & {$[14]$} \\
$\mu_{G}$ & $h a \cdot t^{-1} \cdot y r^{-1}$ & 0.1 & Assumed \\
$\mu_{T}$ & $h a . t^{-1} \cdot y r^{-1}$ & 0.3 & Assumed \\
$\delta_{T}$ & $y r^{-1}$ & $0.03-0.3$ & {$[1]$} \\
$\delta_{G 0}$ & $y r^{-1}$ & 0.1 & $(*)[55]$ \\
$\lambda_{f G}$ & $y r^{-1}$ & $0.1^{(*)}-1^{(* *)}$ & $(* *)[1]$ \\
& & & $(1 *)[23]$ \\
$\lambda_{f T}$ & $y r^{-1}$ & $0.005^{(1 *)}-1^{(2 *)}$ & $(2 *)$ Assumed \\
& & & Assumed \\
$\gamma_{T G}$ & $h a . t^{-1} \cdot y r^{-1}$ & 0.19 & Assumed \\
$\alpha$ & $t . h a^{-1}$ & $0.54-1.73$ & \\
\hline & & &
\end{tabular}

Recent works have shown that NSFD schemes are appropriate to simulate various compartmental models in epidemiology ([5], [6], [21]) and in ecology (4 , [20], 59]). These schemes are able to preserve important properties, like global asymptotic stability of equilibria, backward bifurcation, dissipativity properties, invariant sets, etc.

For the numerical approximation of the model (1), we replace the continuous time variable $t \in$ $[0, \infty)$ by discrete nodes $t_{n}=n h, n \in \mathbb{N}$ where $h=\Delta t>0$ is the step size. We wish to find approximate solutions $G^{n}$ and $T^{n}$ at the time $t=$ 
A. Tchuinté Tamen et al., A Generic Modeling of Fire Impact in a Tree-Grass Savanna Model...

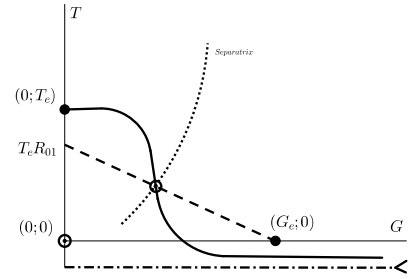

(a)

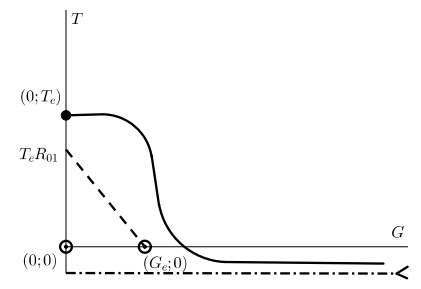

(b)

Fig. 8: Stability/instability of equilibria when $\mathcal{R}_{01}<1$ and $\omega\left(G_{e}\right) R_{10}<1$. Like in Fig 4 (a) shows two stable equilibria: the stable grassland equilibrium and the stable woodland equilibrium (bistability). Fig 6 (b) is different from Fig 4 (b). Here, tree and grass coexistence does not occur; the woodland equilibrium is GAS. Then, the stable internal equilibrium disappears when $\omega\left(G_{e}\right) R_{10}<1$. Thus trees dominate the vegetation. This situation does not occur when we use Holling type II.

$t_{n}$. The standard denominator $h$ in each discrete derivative is replaced by a time-step function $0<$ $\phi(h)<1$, such that $\phi(h)=h+\mathcal{O}\left(h^{2}\right)$.

A possible simple NSFD scheme of Model (1) reads as,

$$
\left\{\begin{array}{l}
\frac{G^{n+1}-G^{n}}{\phi(h)}=\gamma_{G} G^{n}-\delta_{G 0} G^{n+1}-\mu_{G} G^{n} G^{n+1} \\
-\gamma_{T G} T^{n} G^{n+1}-\lambda_{f G} f G^{n+1} \\
\frac{T^{n+1}-T^{n}}{\phi(h)}=\gamma_{T} T^{n}-\delta_{T} T^{n+1}-\mu_{T} T^{n} T^{n+1} \\
-\lambda_{f T} f \omega\left(G^{n}\right) T^{n+1} .
\end{array}\right.
$$

Let $X^{n}=\left(G^{n}, T^{n}\right)^{T}$, be an approximation of $X\left(t_{n}\right)=\left(G\left(t_{n}\right), T\left(t_{n}\right)\right)^{T}$. A nonstandard matrix form of (7) is given by

$$
X^{n+1}=\mathcal{A}\left(X^{n}\right) X^{n},
$$

where $\mathcal{A}\left(X^{n}\right)$ is a diagonal matrice with diagonal terms defined as follows:

$$
\mathcal{A}_{11}=\frac{1+\phi(h) \gamma_{G}}{1+\phi(h)\left(\delta_{G 0}+\lambda_{f G} f+\mu_{G} G^{n}+\gamma_{T G} T^{n}\right)},
$$

and,

$$
\mathcal{A}_{22}=\frac{1+\phi(h) \gamma_{T}}{1+\phi(h)\left(\delta_{T}+\lambda_{f T} f \omega\left(G^{n}\right)+\mu_{T} T^{n}\right)} .
$$

It is obvious that $\mathcal{A}\left(X^{n}\right)$ is nonnegative. Thus,

$$
X^{n} \geq 0 \Longleftrightarrow X^{n+1} \geq 0, \quad \forall n \in \mathbb{N} .
$$

Definition III.1. [7] A numerical scheme is called elementary stable whenever it has no other fixed points than those of the continuous system it approximates, the local stability of these fixed points is the same for both the discrete and the continuous dynamical systems for each value of $h$.

Let us set $x_{*}=\left(G_{*} ; T_{*}\right)^{T}$, an equilibrium of the continuous model (1) and assume that $x_{*}$ is hyperbolic.

Lemma III.1. The numerical scheme (7) and the continuous system (1) have the same equilibria.

The proof of lemma III.1 is provided in Appendix B.

Let a function $\varphi: \mathbb{R} \longrightarrow \mathbb{R}$, satisfy

$$
\left\{\begin{array}{c}
\varphi(z)=z+\mathcal{O}\left(z^{2}\right), \\
0<\varphi(z)<1,
\end{array}\right.
$$

for $z>0$. The denominator function that is needed in (7) can be taken to be

$$
\phi(h)=\frac{\varphi(Q h)}{Q},
$$

where $Q$ is any number which can capture the dynamics of the model (1). $Q$ satisfies

$$
Q \geq \max \left\{\frac{|\lambda|^{2}}{2|\mathcal{R} e \lambda|}\right\},
$$


A. Tchuinté Tamen et al., A Generic Modeling of Fire Impact in a Tree-Grass Savanna Model...

where $\lambda$ denotes an eigenvalue of $J_{*} \equiv J\left(x_{*}\right)$ which is the jacobian matrix of the right hand side of system (1) at $x_{*}$. We have following results.

Lemma III.2. The jacobian matrix $J_{*}$ is diagonalisable.

See Appendix C for the proof of lemma $I I I .2$.

Theorem III.1. The NSFD scheme (7) is elementary stable whenever $\phi(h)$ is chosen according to (11) and (12).

D.

The proof of theorem III.1 is done in Appendix

According to theorem III.1, the continuous and discrete systems (1) and (7) have the same dynamics, at least locally. We now provide some numerical simulations in order to highlight some bifurcation parameters.

\section{NumERICAL Simulations AND DISCUSSION}

Using the previous scheme, we will show that some parameters are bifurcation parameters.

3) Bifurcation due to fire period $\tau$ : In arid and semi-arid savannas, frequent fire pressure influences significantly the balances between tree and grass [45]. Moreover, fire is considered as a major determinant of the ecology and distribution of Africa's savanna and grassland vegetation types [12], [23], [61]. To understand the effects due to fire period $\tau=\frac{1}{f}$, it is helpful to plot some curves. By contrast to the explanations of [9], which show that nonlinear ecosystem dynamics lead to bistable ecological communities that can exist in either a grassland or forest state under the same disturbance frequency, our results suggest that adding a nonlinear fire impact on trees leads to the bistability of two tree-grass coexistence equilibria under certain ecological thresholds. Fig. 9 above illustrates this situation. We can observe how, the system can rapidly move between two coexistence equilibria depending upon the starting conditions. However, in response to gradual changes in fire regimes, the ecosystem globally changes. Further, at ecological thresholds, small shifts in fire regime can lead to disproportionate

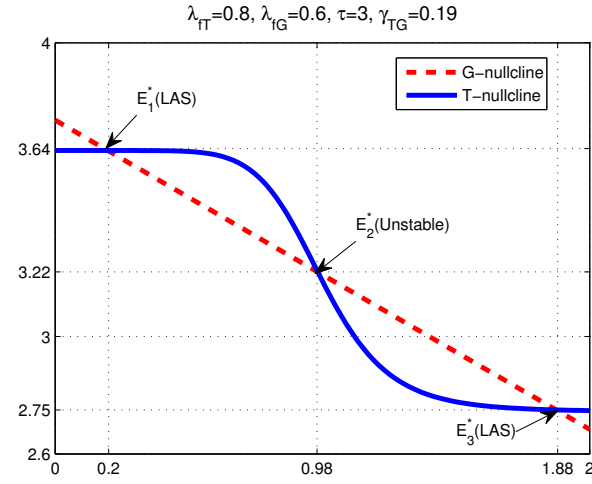

(a)

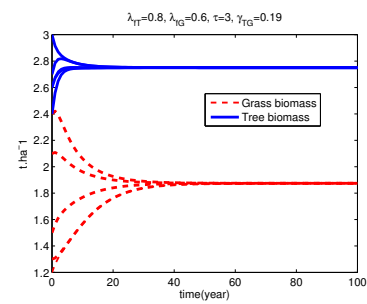

(b)

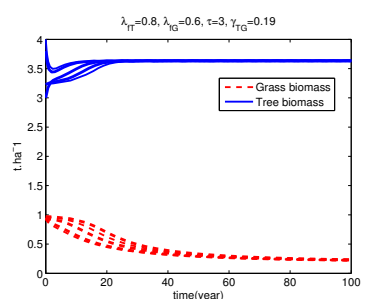

(c)
Fig. 9: (a) phase portrait with $\lambda_{f T}=0.8, \lambda_{f G}=0.6$ $\gamma_{T G}=0.19, f=\frac{1}{\tau}$, and $\tau=3$. Three internal equilibria: $E_{1}^{*}=(0.2 ; 3.64), E_{2}^{*}=(0.98 ; 3.22)$, and $E_{3}^{*}=(1.88 ; 2.75)$. The intermediate point is unstable and the lower and upper points are stable. The trajectory of the system will eventually bifurcate to $E_{1}^{*}$ or $E_{3}^{*}$ depending on its initial condition. (b) and (c) show respectively the local stability of $E_{1}^{*}$ and $E_{3}^{*}$.

changes in ecosystems and ecological surprises or sudden changes in state [42]. For example, for one fire every two years, eventually the configuration will change. See figures 10 and 11 below.

Figures 11-(b) and 11.(c) show that standard methods are not suitably designed for some complex problems. In figure 11-(b), we have used the ode45 routine in Matlab: the result is not nice because the grass biomass becomes negative. The positivity of the solutions and their boundedness are not preserved. Conversely, figure 11-(c) obtained with the nonstandard scheme preserves all the previous qualitative properties; particularly the global asymptotical stability of the woodland vegetation $E_{T_{e}}$. 
A. Tchuinté Tamen et al., A Generic Modeling of Fire Impact in a Tree-Grass Savanna Model...

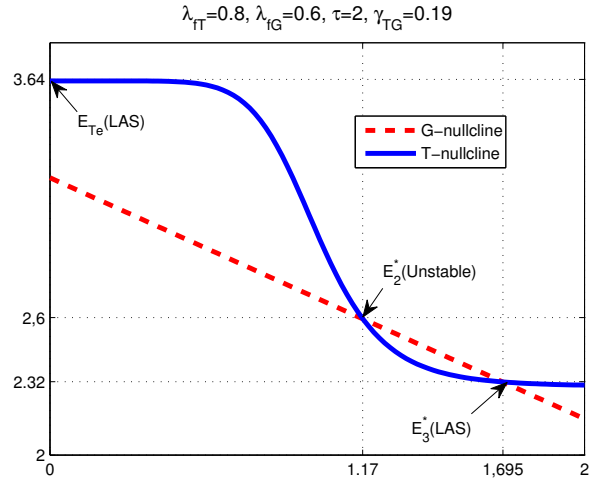

(a)

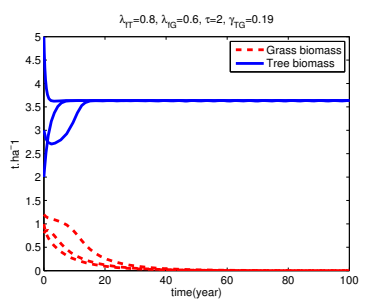

(b)

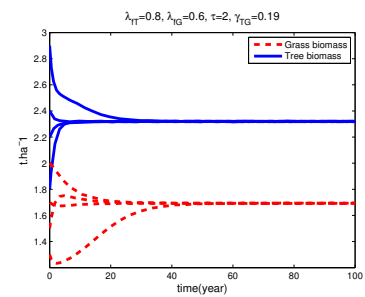

(c)
Fig. 10: The phase plane (a) shows two domains of attraction. The system may move from one domain to another. Then, it can be flipped from a stable state $E_{T_{e}}=(0 ; 3.64)$ (figure (b)) to $E_{3}^{*}=$ $(1.695 ; 2.32)$ (figure (c)) by crossing the unstable intermediate point $E_{2}^{*}$. Here $\tau=2$.

The effect of an increase in $f=\frac{1}{\tau}$ is to shift the G-null cline down and to the left. Hence, the point $E_{1}^{*}$ will approach $E_{T_{e}}$ along the T-null cline. Because the separatrix passes through the point $E_{2}^{*}$, the domain of attraction of $E_{1}^{*}$ must shrink, whereas the domain of attraction of $E_{3}^{*}$ will expand. Then, for higher value of $f$, the points $E_{1}^{*}$ and $E_{T_{e}}$ coincide and change their stability. $E_{T_{e}}$ becomes stable and $E_{1}^{*}$ goes out of domain (Fig $9 \rightarrow 10$. When we still increase $f$, there is only one stable equilibrium for the system $E_{T_{e}}$ $($ Fig $10 \rightarrow 11$. All trajectories approach that point.

4) Bifurcation due to $\lambda_{f G}$ : The specific loss of grass $\lambda_{f G}$ has an important impact in tree-grass interaction (Figure $12 \rightarrow 13$ ). In the region of bistability, the system converged either to a completely herbaceous state (grassland) or to a woody

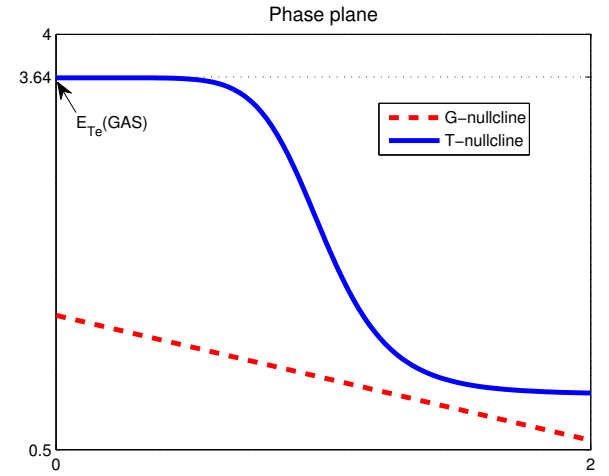

(a)

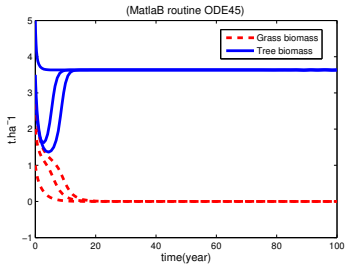

(b)

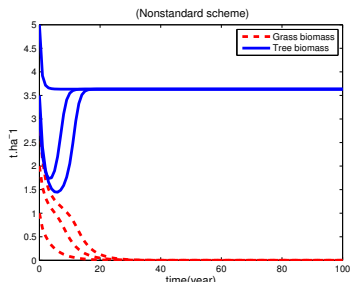

(c)
Fig. 11: (a): when $\tau=1$, there is no Tree-Grass equilibria. The equilibrium $E_{T_{e}}=(0 ; 3.64)$ is globally asymptotically stable. These figures are done for $\lambda_{f T}=0.8, \lambda_{f G}=0.6, \tau=1$ and $\gamma_{T G}=$ 0.19. Simulations are done with (b) the standard ODE45 algorithm; (c) the nonstandard algorithm

equilibrium (forest), depending on the initial values of vegetation. In the region of bistability, a coexistence equilibrium which is unstable exists. Our results joint results of [8].

Increase $\lambda_{f G}$ must shrink the domain of attraction of $E_{G_{e}}$, whereas the domain of attraction of $E_{T_{e}}$ will expand. For a higher value of $\lambda_{f G}$, the points $E_{G_{e}}$ and $E_{2}^{*}$ coincide and change their stability. $E_{G_{e}}$ becomes unstable and there is no coexistence equilibria (Figure $12 \rightarrow 13$ ). Then, for larger values of the grass extinction rate, trees become favoured [8]

5) Bifurcation due to $\gamma_{T G}$ : Trees exert a competitive pressure on grass via water [57]. Figure $14 \rightarrow 15$ illustrate the bifurcation due to $\gamma_{T G}$.

In Figure 14, there are two internal equilibria : $E_{1}^{*}$ is stable and $E_{2}^{*}$ is unstable. The effect 
A. Tchuinté Tamen et al., A Generic Modeling of Fire Impact in a Tree-Grass Savanna Model...

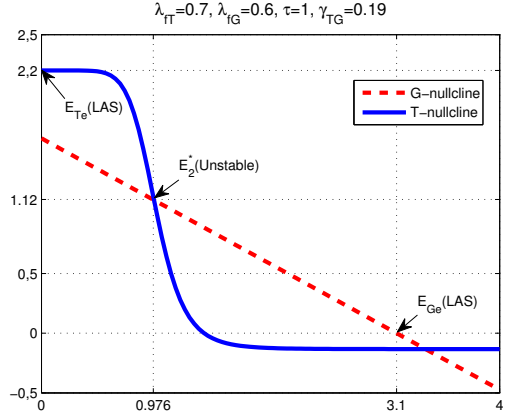

(a)

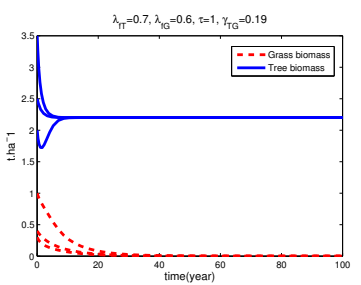

(b)

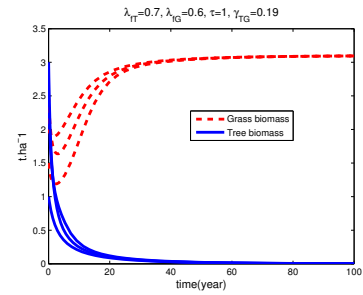

(c)
Fig. 12: (a) shows two basins of attraction: the separatrix which passes through the unstable internal equilibrium $E_{2}^{*}=(0.976 ; 1.12)$ separates the two domains. Trajectories to the right of the separatrix eventually reach $E_{G_{e}}=(3.1 ; 0)$ and those to the left eventually reach $E_{T_{e}}=(0 ; 2.2)$.

(b) stable woody vegetation; (c) stable grassland.

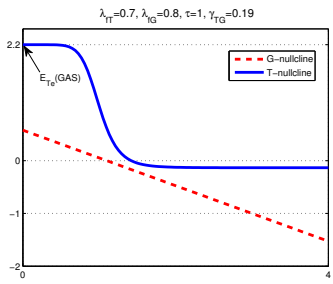

(a)

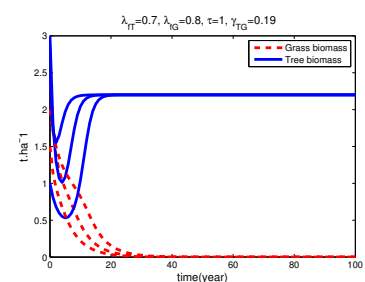

(b)
Fig. 13: Global stability of $E_{T_{e}}=(0 ; 2.2)$.

of a decrease in $\gamma_{T G}$ is to shift de G-null cline up and to the right. The points $E_{1}^{*}$ and $E_{2}^{*}$ will approach each other along the T-null cline and coincide. Because the separatrix passes through the point $E_{2}^{*}$, the domain of attraction of $E_{1}^{*}$ must shrink, whereas the domain of attraction of $E_{G_{e}}$ will expand. For a still lower value of $\gamma_{T G}$, there is

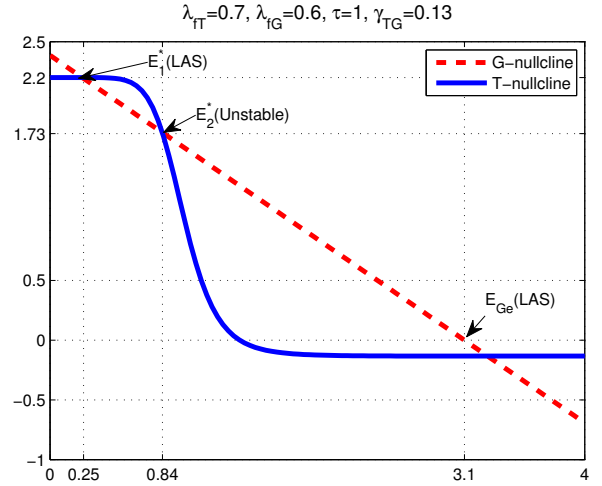

(a)

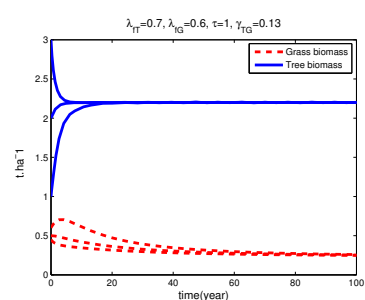

(b)

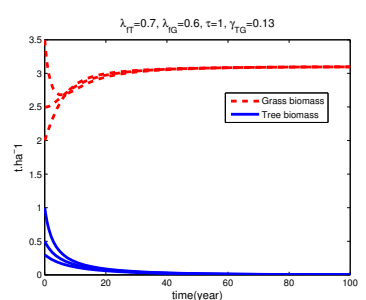

(c)
Fig. 14: (a) Bistability between $E_{1}^{*}=(0.84 ; 2.2)$ and $E_{G_{e}}=$ $(3.1 ; 0)$. Up to the initial conditions, the system may reach: (b) $E_{1}^{*}$, or (c) $E_{G_{e}}$

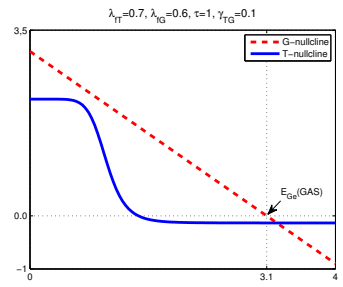

(a)

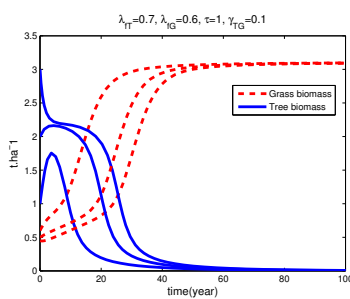

(b)
Fig. 15: (a) and (b) show that equilibrium $E_{G_{e}}=(3.1 ; 0)$ is GAS.

no internal equilibrium and $E_{G_{e}}$ is globally stable (see Fig. 15).

\section{CONCLUSION}

It is well-known that fires shape the tree-grass mixture in savanna-like vegetations as soon as rainfall allows sufficient grass-biomass production 
(for mean annual rainfall above $600-700 \mathrm{~mm}$ ). In those ecosystems where rainfall is sufficient to let woodlands and even closed canopy forests develop and perpetuate, fire is indeed the main factor enabling a long-lasting coexistence of tree and grass components (and even the existence of grassland) in spite of climate conditions favourable to forest. Simple tree-grass competition models have proven their ability to render the main qualitative behaviour of wet savanna systems with multiple equilibria (i.e. grassland, forest and savanna; [1], [36], [55]). But previous models can be questioned with respect to the way in which the crucial fire factor is modeled.

Here we have proposed a new tree-grass competition model which explicitly consider fire impact on woody biomass as a generic monotonously increasing function of the grass biomass, which is seen as an indirect proxy of the ignitable dry grass biomass available at the middle of the dry season. This model deals with tree-grass patterns in arid and semi-arid ecosystems and is able to predict, several equilibria, among which pure cover types i.e. bare soil, grassland, forest along with several levels of tree-grass mixtures. Notably, the number of equilibria featuring tree-grass coexistence depends on the characteristics of the function $\omega(G)$ used to model the fire impact on trees. Moreover, our results featured various bistability situations: between forest and grassland; between forest and one of the tree-grass equilibria with low tree biomass; between grassland and another one coexistence equilibrium with low-grass biomass; and between two tree-grass coexistence equilibria (a stable high-grass equilibrium and a stable lowgrass equilibrium). Thus the system can occupy multiple stable states, and we have identified three thresholds that summarize the long term dynamics of our system: the threshold $\mathcal{R}_{10}$ which represents the net production of tree biomass relative to the fire-induced biomass loss at the grassland equilibrium, the threshold $\mathcal{R}_{01}$ which represents the net primary production of grasses after fire relative to the grass production loss due to the tree biomass at the wooded savanna equilibrium, and the threshold $\mathcal{R}_{11}^{*}$ related to the mixed treegrass equilibrium. Certainly, in the one hand, our continuous tree-grass competition model shows a wealth of possibilities some of which are still to be explored in the light of more detailed assessment of parameters values relating to specific locations within the savanna biome. On the other hand, and in spite of the potential of the present form of the model, one may discuss the modeling options. First, the tree compartment may also be split into two sub-compartments to distinguish trees sensitive to fires and trees that are not (for instance small trees and tall trees). This has been done in [59], where authors consider also a direct negative impact of grass biomass on sensitive trees. This assumption complexifies the continuous model and allows to treating more diverse ecological situations. Second, the modeling of fire as a forcing factor continuous in time may also be questioned.

Preliminary investigations suggest that discreteevent models (with impulsive differential equations (IDE)) can be a way to handle more realistically the influence of fire on tree-grass dynamics. For instance, preliminary results based on the translation of our model into the IDE framework show that periodic equilibria may be observed as well as local and global equilibria. Although it is beyond the scope of the present paper, the next stage will be a thorough analysis of an impulsional version of our model. It is potentially very important to know to what extent fire management may influence vegetation dynamics in fire-prone savanna-like ecosystems.

\section{REFERENCES}

[1] Accatino, F., De Michele, C., Vezzoli, R., Donzelli, D., and Scholes, R. J., (2010) . Tree-grass co-existence in savanna: interactions of rain and fire. 13. J. Theor. Biol. vol. 267, pp. 235-242. http://dx.doi.org/10.1016/j.jtbi.2010.08.012

[2] Andries, J., Janssen, M., Walker, B., (2002) . Grazing management, resilience, and the dynamics of fire-driven rangeland system. Ecosystems 5: 23-44. http://dx.doi.org/10.1007/s10021-001-0053-9

[3] Anguelov, R., Dumont, Y., and Lubuma, J., (2012) . "On Nonstandard Finite Difference Method in Biosciences", AMITANS 2012, AIP Conf. Proc. 1487, pp. 212-223. http://dx.doi.org/10.1063/1.4758961 
A. Tchuinté Tamen et al., A Generic Modeling of Fire Impact in a Tree-Grass Savanna Model...

[4] Anguelov R., Dumont Y., and Lubuma, J.M.-S. (2012). Mathematical Modeling of Sterile Insect Technology for Control of Anopheles Mosquito, Computers and Mathematics with Applications 64 (2012) 374389. http://dx.doi.org/10.1016/j.camwa.2012.02.068

[5] Anguelov, R., Dumont, Y., Lubuma, J. M.-S., and Mureithi, E., (2013). Stability Analysis and Dynamics Preserving Nonstandard Finite Difference Schemes for a Malaria Model, Mathematical Population Studies: An International Journal of Mathematical Demography, 20:2, 101122. http://dx.doi.org/10.1080/08898480.2013.777240

[6] Anguelov, R., Dumont, Y., Lubuma, J. M.-S., and Shillor, M., (2014) . Dynamically consistent nonstandard finite difference schemes for epidemiological models, Journal of Computational and Applied Mathematics, 255, 161182. http://dx.doi.org/10.1016/j.cam.2013.04.042

[7] Anguelov, R., Lubuma, J., (2001) . Contributions to the mathematics of the nonstandard finite difference method and applications, Numer. Methods Partial Differential Eq. 17 (5): 518-543. http://dx.doi.org/10.1002/num.1025

[8] Baudena, M., D’Andrea, F., \& Provenzale, A., (2010). An idealized model for tree-grass coexistence in savannas: the role of life stage structure and fire disturbances. Journal of Ecology, 98, 7480. http://dx.doi.org/10.1111/j.1365-2745.2009.01588.x

[9] Beckage, B., \& Ellingwood, C., (2008) . Fire feedbacks with vegetation and alternative stable states. Complex Systems 18:159-173.

[10] Beckage, B., Platt, W. J., \& Gross, L. J., (2009) . Vegetation, fire and feedbacks: a disturbance-mediated model of savannas. American Naturalist 174:805-818. http://dx.doi.org/0.1086/648458

[11] Bond, W. J., (2008) . What limits trees in C4 grasslands and savannas? Annual Review of Ecology and Systematics 39: 641-659.

http://dx.doi.org/10.1146/annurev.ecolsys.39.110707. 173411

[12] Bond, W. J., Woodward, F. I., Midgley, G. F., (2005) . The global distribution of ecosystems in world without fire, New Phytologist, 165, 525-538

DOI: $10.1111 / j .1469-8137.2004 .01252 . x$.

[13] Breman, H., and De wit, C. T., (1983) . Rangeland productivity and exploitation in the Sahel.-Science 221: 1341-1347. DOI: 10.1126/science.221.4618.1341

[14] Breman, H., \& Kessler, J.-J., (1995) . Woody plants in agro-ecosystems of semi-arid regions. With an emphasis on the Sahelian countries. Advanced series in Agricultural 23, Springer-Verlag, Berlin. 340 p.

[15] Campbell, B., (1996). The miombo in transition, woodlands and welfare in Africa. CIFOR, Bogor, Indonesia.

[16] De Michele, C., Accatino, F., Vezzoli, R., Scholes, R.J., (2011). Savanna domain in the herbivores-fire parameter space exploiting a treegrassoil water dynamic model, journal of Theoretical Biology, vol. 289, pp. 74-89. http://dx.doi.org/10.1016/j.jtbi.2011.08.014

[17] Dercole, F., \& Maggi, S., (2005) . Detection and continuation of a border collision bifurcation in a forest fire model, Applied Mathematics and Computation, 168, 623635. http://dx.doi.org/10.1016/j.amc.2004.09.008

[18] D'Odorico, P., Laio, F., and Ridolfi, L., (2006) . A probabilistic analysis of fire-induced tree-grass coexistence in savannas. The American Naturalist, 167, E79-E87. http://dx.doi.org/doi:10.1086/500617

[19] Dowsett Lemaire, F., (1991). The vegetation of the Kouilou basin in Congo. - In: R.J. Dowsett \& F. DowsettLemaire (éds), Flore et faune $d u$ bassin $d u$ Kouilou (Congo) et leur exploitation, Tauraco Research Report No. 4, Tauraco Press/Conoco, Belgique, p. 17-51.

[20] Dumont, Y., Russell, J.C., Lecomte, V., and Le Corre, M., (2010). Conservation of endangered endemic seabirds within a multi-predator context: The Barau's petrel in Réunion island. Natural Ressource Modelling, 23, pp. 381-436. http://dx.doi.org/10.1111/j.1939-7445.2010.00068.x

[21] Dumont, Y., \& Tchuenche, J., (2012) . Mathematical studies on the sterile insect technique for the chikungunya disease and Aedes albopictus, Journal of Mathematical Biology, vol. 65, no. 5, pp. 809-854. http://dx.doi.org/10.1007/s00285-011-0477-6

[22] Favier, C., Chave, J., Fabing, A., Schwartz, D., \& Dubois, M. A., (2004a). Modelling forest-savanna mosaic dynamics in man-influenced environments: effects of fire, climate and soil heterogeneity. Ecological Modelling 171: 85-102. http://dx.doi.org/10.1016/j.ecolmodel.2003.07.003

[23] Higgins, S. I., Bond, W. J., \& Trollope, W. S. W., (2000) . Fire, resprouting and variability : a recipe for grass-tree coexistence in savanna, Journal of Ecology, 88, 213-229 http://dx.doi.org/10.1046/j.1365-2745.2000.00435.x.

[24] Higgins, S. I., Scheiter, S., \& Sankaran, M., (2010). The stability of African savannas: insights from the indirect estimation of parameters of a dynamic model. Ecology 91: 1682-1692. http://dx.doi.org/10.1890/08-1368.1

[25] Hoffmann, W. A., and Solbrig, O. T., (2003). The role of topkill in the differential response of savanna woody species to fire. Forest Ecology and Management 180, 273 286. http://dx.doi/10.1016/S0378-1127(02)00566-2

[26] House, J. I., Archer, S., Breshears, D. D., Scholes, R. J., and NCEAS, (2003) . Tree-Grass Interactions Participants : Conundrums in mixed woody-herbaceous plant systems. Journal of Biogeography, 30, 1763-1777. DOI: 10.1046/j.1365-2699.2003.00873.x

[27] Kœchlin J., (1961) . La végétation des savanes dans le Sud de la République du Congo (Capitale Brazzaville), Brazzaville, Institut de Recherches Scientifiques au Congo, 310 p., fig., index.

[28] Letouzey R., (1985) . Notice de la carte phytogographyque du Cameroun au 1:500 000, Institut de la Carte Internationale de la Végétation, Toulouse, France.

[29] Lloyd, J., Bird, I., Vellen, L., Miranda, A. C., Veenendaal, E. M., Djagbletey, G., Miranda, H. S., Cook, G., Farqular, G. D., (2008) . Contributions of woody and herbaceous vegetation to tropical savanna ecosystem 
A. Tchuinté Tamen et al., A Generic Modeling of Fire Impact in a Tree-Grass Savanna Model...

productivity: a quasi-global estimate. Tree Physiology 28:451-468.doi: 10.1093/treephys/28.3.451

[30] Ludwig, D., Walker, B., Holling, C. S., (1997a) . Sustainability, stability, and resilience. Conserva Ecol 1(1):http://life.scu.edu.au/consecol/.

[31] Menaut, J. C., (1983) : The vegetation of Africa Savannas. Tropical savannas. Ecosystems of the World, Vol. 13 (ed. by F. Bourlière), pp. 109-149. Elsevier, New York.

[32] Menaut, J. C., \& César, J. (1979). Structure and primary productivity of Lamto savannas, Ivory Coast. Ecology 60: 1197-1210. http://dx.doi.org/10.2307/1936967.

[33] Mickens, R. E., (2000) . Applications of Nonstandard Finite Difference Schemes, World Scientific, Singapore.

[34] Mickens, R. E., (2005) . Advances in the Applications of Nonstandard Finite Difference Schemes, World Scientific, Singapore.

[35] Penning de Vries, F. W. T., and Djitèye, M. A., (eds) (1982) . La productivité des pâturages shéliens. Une étude des sols, des végétations et de l'exploitation de cette ressource naturelle.-PUDOC, Wageningen.

[36] Rietkerk, M., \& van de Koppel, J., (1997) . Alternate stable states and threshold effects in semi-arid grazing systems. -Oikos 79: 69-76.

[37] Russell-Smith, J., Whitehead, P., Cook, G., \& Hoare, J., (2003) . Response of Eucalyptus-dominated savanna to frequent fires: lessons from Munmarlary, 1973-1996. Ecological Monographs 73:349-375.

[38] Sankaran, M., Hanan, N. P., Scholes, R. J., Ratnam, J., Augustine, D. J., Cade, B. S., et al. (2005) . Determinants of woody cover in African savannas. Nature, 438, 846849.http://dx.doi.org/10.1038/nature04070.

[39] Sankaran, M., Ratnam, J., \& Hanan, N., (2008) . Woody cover in African savannas: the role of resources, fire and herbivory. Global Ecology and Biogeography 17:236245. http://dx.doi.org/10.1111/j.1466-8238.2007.00360.x.

[40] Santos, A. J. B., Quesada, C. A., Silva, G. T. D. A., Maiai, J. F., Miranda, H. S., Miranda, A. C., \& Lloyd, J., (2004). High rates of net ecosystem carbon assimilation by Brachiara pasture in the Brazilian cerrado. Global Change Biology, 10, 877-885.

DOI: $10.1111 /$ j.1529-8817.2003.00777.x.

[41] Santos, A. J. B., Silva, G. T. D. A., Miranda, H. S., Miranda, A. C. , \& LIoyd, J., (2003) . Effects of fire on surface carbon, energy and water vapour fluxes over campo sujo savanna in central Brasil. Functionnal Ecology, 17, 711-719. DOI: 10.1111/j.1365-2435.2003.00790.x.

[42] Scheffer M, \& Carpenter, S. R., (2003) . Catastrophic regime shifts in ecosystems: linking theory to observations. TRENDS in Ecology and Evolution 18: 648-656. DOI: 10.1016/j.tree.2003.09.002.

[43] Scholes, R. J., (2003) . Convex relationships in ecosystems containing mixtures of trees and grass. Environmental and Resource Economics 26:559-574.

DOI: 10.1023/B:EARE.0000007349.67564.b3

[44] Scholes, R. J., and Archer, S. R., (1997) . Tree-grass interactions in savannas. Annual Review of Ecology and
Systematics vol. 28, pp. 517-544.

DOI: 10.1146/annurev.ecolsys.28.1.517.

[45] Scholes, R. J., and Walker, B. H., (1993) . An African savanna: synthesis of the Nylsvley study. Cambridge University Press, Cambridge, UK.

[46] Schwinning, S., Sala, O. E., Loik, M. E., and Ehleringer, J. R., (2004) . Thresholds, memory, and seasonality: understanding pulse dynamics in arid/semi-arid ecosystems: Oecologia, 141, 191-193. http://dx.doi.org/10.1007/s00442-004-1683-3

[47] Staver, A. C., Archibald, S., Levin, S., (2011) . Tree cover in sub-Saharan Africa : rainfall and fire constrain forest and savanna as alternative stable states, Ecology, 92(5), 1063-72. http://dx.doi.org/10.1890/10-1684.1

[48] Suchel, J. B., (1988). Les climats du Cameroun. Thèse Doc. es Lettres Univ. Bordeaux III, 3 tomes, p. 1175 et cartes hors texte.

[49] Schwartz, D., (1988). Histoire d'un paysage : le lousseke. Paleoenvironnements quaternaires et podzolisation sur sables Bateke (quarante derniers millénaires, région de Brazzaville, R.P. du Congo). - Collect. Etudes et Thèses, ORSTOM, Paris, 285 p.

[50] Schwartz D., Dechamps, R., Elenga, H., Lanfranchi, R., Mariotti, A., \& Vincens, A., (1995). Savannas in the Congo: An upper Holocene specific vegetation type, 2nd Symposium on African Palynology, Tervuren (Belgium), Publ. Occas. CIFEG, 1995/31, Orléans, CIFEG, p. 99108.

[51] Thonicke K., Venevsky, S., Sitch, S., Cramer, W., (2001) . The role of fire disturbance for global vegetation $d y$ namics: coupling fire into a dynamic global vegetation model. Global Ecology and Biogeography 10: 661-677. DOI:10.1046/j.1466-822X.2001.00175.x.

[52] Tilman, D., (1994) . Competition and biodiversity in spatially structured habitats. Ecology 75 , 2-16. DOI: $10.2307 / 1939377$

[53] Trollope, W. S. W., Trollope L. A., Hartnett D. C., (2002) . Fire behaviour a key factor in the fire ecology of African grasslands and savannas. In: Forest Fire Research \& Wildland Fire Safety. Millpress, Rotterdam, the Netherlands. pp. 1-15.

[54] Van de Vijver, C. A. D. M., Foley, C. A., \& Olff, H., (1999) . Changes in the woody component of an East African savanna during 25 years. Journal of Tropical Ecology 15: 545-564.

[55] van Langevelde, F., et al . Effects of fire and herbivory on the stability of savanna ecosystems, Ecological Society of America, 84(2), 2003, pp. 337-350. DOI, 10.1890/00129658(2003)084[0337:EOFAHO]2.0.CO;2

[56] VanWilgen, B. W., \& Scholes, R. J., (1997) . The vegetation and fire regimes of southern hemisphere Africa. In: Fire in Southern African Savannas: Ecological and Atmospheric Perspectives (eds Andreae MO, Goldammer $J G$, Lindsay K), pp. 27-46. Witwatersrand University Press, Johannesburg, South Africa.

[57] Walker, B. H., Ludwig, D., Holling, C. S., \& Peterman, 
A. Tchuinté Tamen et al., A Generic Modeling of Fire Impact in a Tree-Grass Savanna Model...

R. M., (1981) . Stability of Semi-Arid Savanna Grazing Systems, Journal of Ecology, Vol. 69, $N_{0}$. 2. pp. 473-498

[58] Walter, H., (1971) . Ecology of tropical and subtropical vegetation. Oliver and Boyd, Edinburgh, UK.

[59] Yatat V., Dumont Y., Tewa J.J., Couteron P., and Bowong S., (2014), Mathematical Analysis of a size structured Tree-Grass model in Savanna Ecosystems, BIOMATH 3 (2014), 1404212 http://dx.doi.org/10.11145/j.biomath.2014.04.212

[60] Youta Happi, J. (1998). Arbres contre graminées: la lente invasion de la savane par la forêt au CentreCameroun. Thèse, Université de Paris IV.

[61] Zogning, A., (1979) . Le "Golfe de Bafia", études climatiques. Mém. de Maîtrise, Univ. de Yaoundé, 185 $P$.

Appendix A: Proof of the proposition II.1

The jacobian matrix of the system (1) is given by

$$
J_{(G, T)}=\left(\begin{array}{cc}
J_{11}(G, T) & J_{12}(G, T) \\
J_{21}(G, T) & J_{22}(G, T)
\end{array}\right),
$$

where,

$$
\begin{aligned}
& J_{11}(G, T)=\left(\gamma_{G}-\delta_{G 0}-\lambda_{f G} f\right)-2 \mu_{G} G-\gamma_{T G} T, \\
& J_{12}(G, T)=-\gamma_{T G} G, \\
& J_{21}(G, T)=-\lambda_{f T} f \omega^{\prime}(G) T, \text { and } \\
& J_{22}(G, T)=\left(\gamma_{T}-\delta_{T}\right)-2 \mu_{T} T-\lambda_{f T} f \omega(G) .
\end{aligned}
$$

Now, we analyze the jacobian matrix near the equilibria of system (1).

1) Stability of the bare soil $(0 ; 0)$.

The jacobian matrix of system (1) at the equilibrium point $(0 ; 0)$ is

$$
J_{(0,0)}=\left(\begin{array}{cc}
\left(\gamma_{G}-\delta_{G 0}-\lambda_{f G} f\right) & 0 \\
0 & \left(\gamma_{T}-\delta_{T}\right)
\end{array}\right) .
$$

The eigenvalues of $J(0 ; 0)$ are $\eta_{1}=\gamma_{G}-\delta_{G 0}-\lambda_{f G} f$, and $\eta_{2}=\gamma_{T}-\delta_{T}$. In the domain $\Gamma$, we have $\eta_{1}>0$, and $\eta_{2}>0$. Since, $(0 ; 0)$ has two unstable maniflolds, thus $(0 ; 0)$ is always unstable.

2) Stability of the savanna grassland equilibrium $E_{G_{e}}=\left(G_{e} ; 0\right)=$ $\left(\frac{\gamma_{G}-\delta_{G 0}-\lambda_{f G} f}{\mu_{G}} ; 0\right)$.
The jacobian matrix of system (1) at the equilibrium point $E_{G_{e}}$ is given by

$J_{\left(G_{e}, 0\right)}=\left(\begin{array}{cc}J_{11}\left(\left(G_{e}, 0\right)\right) & J_{12}\left(\left(G_{e}, 0\right)\right) \\ 0 & J_{22}\left(\left(G_{e}, 0\right)\right)\end{array}\right)$,

where,

$$
\begin{aligned}
J_{11}\left(\left(G_{e}, 0\right)\right) & =-\left(\gamma_{G}-\delta_{G 0}-\lambda_{f G} f\right), \\
J_{12}\left(\left(G_{e}, 0\right)\right) & =-\gamma_{T G} G_{e}, \quad \text { and } \\
J_{22}\left(\left(G_{e}, 0\right)\right) & =\lambda_{f T} f \omega\left(G_{e}\right)\left(R_{10}-1\right) . \\
R_{10} & =\frac{\gamma_{T}-\delta_{T}}{\lambda_{f T} f} \frac{1}{\omega\left(G_{e}\right)} .
\end{aligned}
$$

The corresponding eigenvalues of $J_{\left(G_{e}, 0\right)}$ are $\nu_{1}=-\left(\gamma_{G}-\delta_{G 0}-\lambda_{f G} f\right)<0$, and $\nu_{2}=$ $\lambda_{f T} f \omega\left(G_{e}\right)\left(R_{10}-1\right)$. Therefore,

- If $R_{10}<1$, then $E_{G_{e}}$ is asymptotically stable.

- If $R_{10}>1$, then $E_{G_{e}}$ is a saddle point (unstable).

3) Stability of the wooded savanna equilibrium $E_{T_{e}}=\left(0 ; T_{e}\right)=\left(0 ; \frac{\gamma_{T}-\delta_{T}}{\mu_{T}}\right)$.

According to the system (1), the jacobian matrix at the equilibrium point $E_{T_{e}}$ can be written as

$J_{\left(0, T_{e}\right)}=\left(\begin{array}{cc}\gamma_{T G} T_{e}\left(R_{01}-1\right) & 0 \\ -\lambda_{f T} f \omega^{\prime}(0) T_{e} & -\left(\gamma_{T}-\delta_{T}\right)\end{array}\right)$,

where,

$$
\mathcal{R}_{01}=\frac{\gamma_{G}-\delta_{G 0}-\lambda_{f G} f}{\gamma_{T G}} \frac{\mu_{T}}{\gamma_{T}-\delta_{T}} .
$$

The two eigenvalues of $J_{\left(0, T_{e}\right)}$ are $\sigma_{1}=$ $\gamma_{T G} T_{e}\left(R_{01}-1\right)$, and $\sigma_{2}=-\left(\gamma_{T}-\delta_{T}\right)<0$. We obtain these following conclusions,

- If $R_{01}<1$, then $E_{T_{e}}$ is asymptotically stable.

- If $R_{01}>1$, then $E_{T_{e}}$ is a saddle point (unstable).

4) Stabilility of the tree-grass coexistence equilibrium $E^{*}=\left(G^{*} ; T^{*}\right)$. 
A. Tchuinté Tamen et al., A Generic Modeling of Fire Impact in a Tree-Grass Savanna Model...

The fixed equilibrium point $\left(G^{*} ; T^{*}\right)$ is determined as the positive solution of system

$$
\left\{\begin{array}{l}
\left(\gamma_{G}-\delta_{G 0}-\lambda_{f G} f\right)-\mu_{G} G^{*}-\gamma_{T G} T^{*}=0, \\
\left(\gamma_{T}-\delta_{T}\right)-\mu_{T} T^{*}-\lambda_{f T} f \omega\left(G^{*}\right)=0 .
\end{array}\right.
$$

Using $(13)$, the jacobian matrix of the system (1) at $E^{*}=\left(G^{*} ; T^{*}\right)$ is given by

$$
J_{\left(G^{*} ; T^{*}\right)}=\left(\begin{array}{cc}
-\mu_{G} G^{*} & -\gamma_{T G} G^{*} \\
-\lambda_{f T} f \omega^{\prime}\left(G^{*}\right) T^{*} & -\mu_{T} T^{*}
\end{array}\right) .
$$

The eigenvalues of the jacobian matrix at the internal equilibrium $E^{*}$ satisfy the following relations

- $\theta_{1}+\theta_{2}=-\mu_{G} G^{*}-\mu_{T} T^{*}<0$, and

- $\theta_{1} \theta_{2}=\gamma_{T G} \lambda_{f T} f \omega^{\prime}\left(G^{*}\right) G^{*} T^{*}\left(R_{11}^{*}-\right.$ $1)$,

where,

$R_{11}^{*}=\frac{\mu_{G} \mu_{T}}{\gamma_{T G} \lambda_{f T} f} \frac{1}{\omega^{\prime}\left(G^{*}\right)}=\mathcal{R}_{10} \mathcal{R}_{01} \frac{\omega\left(G_{e}\right)}{\omega^{\prime}\left(G^{*}\right) G_{e}}$.

Clearly, according to $\theta_{1} \theta_{2}$ which is the product of the two eigenvalues of $J_{\left(G^{*} ; T^{*}\right)}$, we have,

- If $R_{11}^{*}<1$, then $E^{*}$ is unstable.

- If $R_{11}^{*}>1$, then $E^{*}$ is asymptotically stable.

This end the proof of the proposition $I I .1$.

Appendix B: Proof of lemma $I I I .1$

If $x_{*}$ is an equilibrium of the continuous system (1), then we have

$$
\left\{\begin{array}{l}
\left(\gamma_{G}-\delta_{G 0}-\lambda_{f G} f\right) G_{*}-\mu_{G} G_{*}^{2}-\gamma_{T G} T_{*} G_{*}=0, \\
\left(\gamma_{T}-\delta_{T}\right) T_{*}-\mu_{T} T_{*}^{2}-\lambda_{f T} f \omega\left(G_{*}\right) T_{*}=0 .
\end{array}\right.
$$

Multiplying both sides of the two equations of (14) by $\phi(h)$, leads to the following system:

$\left\{\begin{array}{l}\phi(h) \gamma_{G} G_{*}=\phi(h)\left(\delta_{G 0}+\lambda_{f G} f+\mu_{G} G_{*}+\gamma_{T G} T_{*}\right) G_{*}, \\ \phi(h) \gamma_{T} T_{*}=\phi(h)\left(\delta_{T}+\lambda_{f T} f \omega\left(G_{*}\right)+\mu_{T} T_{*}\right) T_{*} .\end{array}\right.$
In (15), adding $G_{*}$ and $T_{*}$ in both sides of the first equation and the second equation respectively, gives

$$
\left\{\begin{array}{l}
\left(1+\phi(h) \gamma_{G}\right) G_{*}=\left[1+\phi(h)\left(\delta_{G 0}+\lambda_{f G} f\right.\right. \\
\left.\left.+\mu_{G} G_{*}+\gamma_{T G} T_{*}\right)\right] G_{*} \\
\left(1+\phi(h) \gamma_{T}\right) T_{*}=\left[1+\phi(h)\left(\delta_{T}+\lambda_{f T} f \omega\left(G_{*}\right)\right.\right. \\
\left.\left.+\mu_{T} T_{*}\right)\right] T_{*} .
\end{array}\right.
$$

System 16 is equivalent to the following one

$$
\left\{\begin{array}{l}
\mathcal{A}_{11} G_{*}=G_{*}, \\
\mathcal{A}_{22} T_{*}=T_{*} .
\end{array}\right.
$$

Thus, we have

$$
\mathcal{A}\left(x_{*}\right) x_{*}=x_{*} .
$$

Then $x_{*}$ is an equilibrium of the discrete system (7).

Appendix C: Proof of lemma $I I I .2$

The jacobian matrix of right hand side of the system (1) at $x_{*}$ is given by

$$
J_{*}=\left(\begin{array}{cc}
J_{11}\left(x_{*}\right) & J_{12}\left(x_{*}\right) \\
J_{21}\left(x_{*}\right) & J_{22}\left(x_{*}\right)
\end{array}\right),
$$

where,

$J_{11}\left(x_{*}\right)=\left(\gamma_{G}-\delta_{G 0}-\lambda_{f G} f\right)-2 \mu_{G} G_{*}-\gamma_{T G} T_{*}$,

$J_{12}\left(x_{*}\right)=-\gamma_{T G} G_{*}$,

$J_{21}\left(x_{*}\right)=-\lambda_{f T} f \omega^{\prime}\left(G_{*}\right) T_{*}, \quad$ and

$J_{22}\left(x_{*}\right)=\left(\gamma_{T}-\delta_{T}\right)-2 \mu_{T} T_{*}-\lambda_{f T} f \omega\left(G_{*}\right)$.

The eigenvalues of $J_{*}$ are solutions of the following equation

$$
\lambda^{2}-\operatorname{tr}\left(J_{*}\right) \lambda+\operatorname{det}\left(J_{*}\right)=0,
$$

where

$$
\begin{aligned}
& \operatorname{tr}\left(J_{*}\right)=J_{11}\left(x_{*}\right)+J_{22}\left(x_{*}\right), \quad \text { and } \\
& \operatorname{det}\left(J_{*}\right)=J_{11}\left(x_{*}\right) J_{22}\left(x_{*}\right)-J_{12}\left(x_{*}\right) J_{21}\left(x_{*}\right) .
\end{aligned}
$$


A. Tchuinté Tamen et al., A Generic Modeling of Fire Impact in a Tree-Grass Savanna Model...

The sign of each eigenvalue depends of the discriminant $\Delta$ of equation 19 :

$$
\begin{aligned}
\Delta & =\left(\operatorname{tr}\left(J_{*}\right)\right)^{2}-4 \operatorname{det}\left(J_{*}\right) \\
& =\left(J_{11}\left(x_{*}\right)-J_{22}\left(x_{*}\right)\right)^{2}+4 J_{12}\left(x_{*}\right) J_{21}\left(x_{*}\right) .
\end{aligned}
$$

If $\Delta>0$, then $J_{*}$ is diagonalisable. We have

$$
J_{12}\left(x_{*}\right) J_{21}\left(x_{*}\right)=\gamma_{T G} \lambda_{f T} f \omega^{\prime}\left(G_{*}\right) T_{*} G_{*} \geq 0 .
$$

Then $\Delta>0$. Therefore $J_{*}$ is diagonalisable.

Appendix D: Proof of theorem $I I I .1$

Here, we can easily adapted the proof of theorem 8 in [6]. We have shown in lemma III.1 that, the NSFD scheme (7) has no extra fixed points than those of (1). We have also shown in lemma $I I I .2$ that, the jacobian matrix $J_{*}$ is diagonalisable. Thus, $\lambda_{1}$ and $\lambda_{2}$ being the eigenvalues of $J_{*}$, there exists a transition matrix $P$ such that

$$
P^{-1} J_{*} P=\operatorname{diag}\left(\lambda_{1}, \lambda_{2}\right) .
$$

The linearization of system (1) at $x_{*}$ reads as

$$
\frac{d \tilde{x}}{d t}=J_{*} \tilde{x},
$$

where $\tilde{x}=x-x_{*}$. System 21 is equivalent to

$$
\frac{d \tilde{y}}{d t}=\operatorname{diag}\left(\lambda_{1}, \lambda_{2}\right) \tilde{y}
$$

Thus, applying the NSFD scheme (7) to system 21) or 22, we obtain the linearized scheme

$$
\tilde{x}^{n+1}=\left(I-\phi(h) J_{*}\right) \tilde{x}^{n},
$$

or

$$
\tilde{y}^{n+1}=\operatorname{diag}\left(\frac{1}{1-\phi(h) \lambda_{1}}, \frac{1}{1-\phi(h) \lambda_{2}}\right) \tilde{y}^{n} .
$$

Set $\varphi_{*}=\varphi\left(\left(I-\phi(h) J_{*}\right)^{-1}\right)$. It follows from 24 that,

$$
\varphi_{*}=\max \left\{\frac{1}{\left|1-\phi(h) \lambda_{1}\right|}, \frac{1}{\left|1-\phi(h) \lambda_{2}\right|}\right\} .
$$

Recall that, if $x_{*}$ is asymptotically stable for (1), then for all $i \in\{1,2\}$, we have $\left|\mathcal{R} e\left(\lambda_{i}\right)\right|=$ $-\mathcal{R} e\left(\lambda_{i}\right)$. Thus

$\varphi_{*}=\max _{1 \leq i \leq 2}\left\{\frac{1}{\sqrt{1+2 \phi(h)\left|\mathcal{R} e\left(\lambda_{i}\right)\right|+\phi^{2}(h)\left|\lambda_{i}\right|^{2}}}\right\}<1$,

which shows that $x_{*}$ is asymptotically stable for the scheme (7).

If $x_{*}$ is unstable for (1), then there exists at least one eigenvalue of $J_{*}, \lambda$ with positive real part. We then have,

$$
\frac{1}{|1-\phi(h) \lambda|}=\frac{1}{\sqrt{1-2 \phi(h) \mathcal{R} e(\lambda)+\phi^{2}(h)|\lambda|^{2}}}>1,
$$

whenever condition (12) holds. Therefore, $x_{*}$ is unstable for scheme $(7)$. Thus, the discrete scheme (7) preserves stability/instability properties of the continuous model (1). 